\title{
Editorial
}

\section{Cardiovascular problems in divers}

Scuba diving is one of the most rapidly growing participant sports. Commercial diving is of economic importance and necessary for public safety-for example, in offshore oil exploration and underwater inspection of bridge supports and ships hulls. Diving involves physiological stresses that are not encountered in other circumstances, so that the fitness requirements for divers differ from other sports and occupations. There are variations in regulations between nations and organisations. In the United Kingdom the medical requirements are laid out in regulations issued by the Health and Safety Executive for professional divers and in guidelines issued by the United Kingdom Sport Diving Medical Committee for amateur divers. As a general rule, any condition that causes a significantly increased risk of incapacity in or under water or that predisposes to diving related disease will disqualify an individual from diving.

\section{Physiological effects of diving}

Immersion alone (which occurs in water at a temperature near to body temperature) rapidly redistributes blood from the legs to the thorax. This increases intrathoracic blood volume by up to $700 \mathrm{ml}$, right atrial pressures by $18 \mathrm{~mm} \mathrm{Hg}$, cardiac output by over $30 \%$, and blood pressure slightly. ${ }^{12}$ To correct the increased central blood volume natriuresis and diuresis are stimulated. After immersion for many hours the reduction in plasma volume can be so great that when a casualty is removed from the water and hydrostatic support of venous return is removed hypovolaemic shock and sometimes death may result.

The seas are colder than body temperature. Water has thermal capacity and thermal conductivity, respectively, about 3000 and 32 times greater than air. The venoconstrictor effects of cold potentiate the effects of immersion by increasing filling pressures further, but more importantly arteriolar constriction increases blood pressure, left ventricular wall stress, and myocardial oxygen consumption. ${ }^{3}$ Bradyarrhythmias induced by cold immersion, particularly with breath-holding, are well described..$^{45}$ The mechanisms involved are potent and the bradycardia on initial immersion in very cold water can be so prolonged that it causes unconsciousness and drowning-so called hydrocution. Tachyarrhythmias can also occur. I have witnessed ventricular tachycardia during cold immersion in a diver with coronary artery disease.

The partial pressure of oxygen in the gas breathed (the product of ambient pressure and the proportion of the gas in the mixture) when diving is greater than in air at sea level. At higher partial pressures, oxygen also acts as a vasoconstrictor. ${ }^{6}$ It increases blood pressure, reduces cardiac output, and reduces heart rate. In addition to these physiological responses are those that result from the exertion involved in swimming and the neuroendocrine effects of stress that is often present during more challenging dives.

\section{Diving induced pulmonary oedema}

Occasionally otherwise healthy individuals develop pulmonary oedema when diving and swimming ${ }^{7-9}$; the mechanism is debated. The findings in the original and largest series of observations in divers and swimmers suggested that the mechanism was an accentuation of normal vasoconstrictor responses (particularly in response to cold) sufficient to cause cardiac decompensation. ${ }^{7}$ In some individuals, forearm vascular resistance was increased by cold stimulation to levels observed in patients with phaeochromocytoma. ${ }^{7}$ During long term follow up most of these individuals developed systemic hypertension. ${ }^{7}$ In other studies, pathological exercise-induced increases in flows were thought to be responsible. ${ }^{89}$ The precise cause of this condition is uncertain. Individuals affected once are at increased risk of further episodes and should be advised not to dive again. Some divers refuse to accept this advice. Nifedipine reduces the pathological vasoconstrictor responses to physiological stimuli in individuals with diving induced pulmonary oedema (Wilmshurst, unpublished data). Therefore, for 15 years, when divers refuse to follow advice to give up the sport after suffering diving induced pulmonary oedema, I have suggested that they take $5 \mathrm{mg}$ nifedipine before diving. As far as I am aware none that did so had a recurrence of diving induced pulmonary oedema. Diving induced pulmonary oedema is relatively rare and most sufferers accept the advice not to dive again, so there have been inadequate numbers for a placebo controlled trial of nifedipine but it is my clinical impression in a few cases that nifedipine may be helpful.

\section{Hypertension and structural heart disease}

Individuals with significant hypertension or left ventricular dysfunction as a result of cardiomyopathy, coronary artery disease or valvar disease are considered at increased risk of pulmonary oedema when diving, which represents a contraindication to participation. Mild abnormalities may be permitted in amateur divers. Even without impaired left ventricular function, individuals with symptomatic coronary artery disease should not dive. Resumption of professional and amateur diving has been permitted in divers who were rendered asymptomatic and had a normal exercise performance without evidence of ischaemia after coronary angioplasty. Amateur diving has been permitted after coronary artery surgery when the same requirements have been satisfied, provided that surgery did not cause lung injury, which might predispose to pulmonary barotrauma. In cases where the individual has had documented coronary artery disease the subsequent reviews of medical fitness to dive are at more frequent intervals and involve more stringent tests than in other divers.

Significant valve stenosis impairs the response to exercise and therefore disqualifies an individual from diving. Aortic stenosis where there is a risk of syncope on exertion, and mitral stenosis in which pulmonary oedema may be precipitated, are considered particularly high risks. Individuals with prosthetic valves are considered on an individual basis for amateur diving.

\section{Arrhythmias and pacing}

The decision to allow an individual who has cardiac arrhythmias to dive is based on a number of considerations: the frequency and duration of attacks, anticipated degree of incapacity that might occur during an attack underwater, whether circumstances when diving (such as cold) might precipitate an attack, and coincidental structural 
heart disease. An individual rendered asymptomatic by pathway ablation or pacing may be permitted to dive, but these interventions both present special problems.

Pacemaker cans are compressed by the increased hydrostatic pressures underwater. All pacemakers will fail with potentially fatal consequences if taken deep enough. The can mounted sensors of rate responsive pacemakers often fail at shallow depths, so rate response is lost on descent, but should return on surfacing, unless the pacemaker is taken so deep that permanent can distortion occurs. There are considerable variations in the depths to which individual pacemakers are tested-for example, Vitatron Collection II and Vita pacemakers (Vitatron UK Ltd, Bucks, UK) are tested to a pressure equivalent to $11 \mathrm{~m}$ sea water; Medtronic (Minneapolis, Minnesota, USA) recommend that Thera, Prodigy, and Elite II pacemakers should not be exposed to pressures greater than at $30 \mathrm{~m}$ sea water (although during tests function was reversibly affected at shallower depths); and the Intermedic Dash 292-03 (Intermedics, Angleton, USA) has been tested to $60 \mathrm{~m}$ (data supplied by manufacturers). The last pacemaker is acceptable for use in the air diving range (to $50 \mathrm{~m}$ ) and this leaves a small safety margin if the diver descends a little deeper. Pacemakers that have been tested to shallower depth should not be implanted in divers (or in individuals who might require hyperbaric oxygen therapy). No pacemaker is safe at the great depths dived by mixed gas commercial divers, who may be working $150 \mathrm{~m}$ deep in the northern sector of the North Sea or even deeper in other countries. Deep commercial diving is not permitted in those with an implanted pacemaker.

When left sided pathways are ablated using an interatrial transseptal puncture, a right to left shunt may be produced, which poses the possibility of an increased risk of decompression illness.

\section{Intracardiac shunts}

A right to left shunt that would be too small to produce symptoms in any other circumstance, may be associated with certain types of decompression illness. ${ }^{10-12}$ In these cases shunting is usually across a large patent foramen ovale but other types of atrial septal defects and pulmonary arteriovenous malformations may be responsible. ${ }^{13}$ The presence of such a shunt should be considered particularly if the diver first noticed neurological symptoms within 30 minutes of surfacing from a dive with a theoretically safe decompression profile. Cutaneous and cardiorespiratory decompression illness are also often associated with shunts, but joint pains are not. ${ }^{11}{ }^{12}$ Atrial shunts may be closed by percutaneous transvenous techniques to permit resumption of diving after episodes of shunt mediated decompression illness. ${ }^{14}$ Balloon sizing at the time of closure has demonstrated that the defects are generally about $1 \mathrm{~cm}$ diameter or greater. ${ }^{14}$ This is considerably larger than the usual size of patent foramen ovale but in accord with observations in patients with paradoxical thromboembolism. ${ }^{15}$ This explains why only a minority of divers with patent foramen ovale suffer decompression illness by this mechanism. There are concerns that other divers with right to left shunts may suffer recurrent neurological insults, which do not cause episodes of frank decompression illness but may lead to neurological deficits later. ${ }^{16}$

Consultant Cardiologist,

The Royal Shrewsbury Hospital,

Shrewsbury $S Y 38 X Q$, UK

1 Hong SK, Cerretelli P, Cruz JC, et al. Mechanics of respiration during submersion in water. $\mathcal{F}$ Appl Physiol 1969;27:535-8.

2 Arborelius M, Balldin UI, Lilja B, et al. Hemodynaic changes in man during immersion with the head above water. Aerosp Med 1972;43:592-8.

3 Keatinge WR, McIlroy MB, Goldfien A. Cardiovascular responses to ice-cold showers. F Appl Physiol 1964;19:1145-50.

4 Song SH, Lee WK, Chung YA, et al. Mechanisms of apneic bradycardia in man. F Appl Physiol 1969;27:323-7.

5 Hong SK, Song SH, Kim PK, et al. Seasonal observations on the cardiac rhythm during diving in the Korean Ama. F Appl Physiol 1967;23:18-22.

6 Bird AD, Telfer ABM. Effects of hyperbaric oxygen on limb circulation. Lancet 1965;i:355-6.

7 Wilmshurst PT, Nuri $M$, Crowther A, et al. Cold-induced pulmonary oedema in scuba divers and swimmers and subsequent development of oedema in scuba divers and swim
hypertension. Lancet 1989;i:62-5.

8 Pons M, Blickenstorfer D, Oechslin E, et al. Pulmonary oedema in healthy Pons M, Blickenstorfer D, Oechslin E, et al. Pulmonary oedema in heal hy
persons during scuba-diving and swimming. Eur Resp f 1995;8:762-7.

9 Weiler-Ravell D, Shupak A, Goldenberg I, et al. Pulmonary oedema and haemoptysis induced by strenuous swimming. BMF 1995;311:361-2.

10 Moon RE, Camporesi EM, Kisslo JA. Patent foramen ovale and decompression sickness in divers. Lancet 1989;i:513-14.

1 Wilmshurst PT, Byrne JC, Webb-Peploe MM. Relation between interatrial shunts and decompression sickness in divers. Lancet 1989;ii:1302-6.

12 Wilmshurst PT, Byrne JC, Webb-Peploe MM. Relation between interatrial shunts and decompression sickness in divers. In: Sterk W, Geeraedts L, eds. EUBS 1990 Proceedings. Amsterdam: European Undersea Biomedical Society 1990:147-53.

13 Wilmshurst P, Walsh K, Morrison L. Patent foramen ovale and decompression illness in divers. Lancet 1997;349:288.

14 Walsh KP, Wilmshurst PT, Morrison WL. Transcatheter closure of patent foramen ovale using Amplatzer septal occluder to prevent recurrence of foramen ovale using Amplatzer septal occluder to prevent recur
neurological decompression illness in divers. Heart. [In press.]

15 Hausmann D, Mugge A, Daniel WG. Identification of patent foramen ovale permitting paradoxical embolism. F Am Coll Cardiol 1995;26:1030-8.

16 Knauth M, Ries S, Pohimann S, et al. Cohort study of multiple brain lesions in sports divers: role of a patent foramen ovale. BMF 1997;314:701-5. 